\title{
Effect of alcohol-gasoline blends optimization on fuel properties, performance and emissions of a SI engine
}

\author{
B.M. Masum*, H.H. Masjuki, M.A. Kalam*, S.M. Palash, M. Habibullah
}

Centre for Energy Sciences, Faculty of Engineering, University of Malaya, 50603 Kuala Lumpur, Malaysia

A R T I C L E I N F O

Article history:

Received 21 May 2014

Received in revised form

7 July 2014

Accepted 3 August 2014

Available online 27 August 2014

Keywords:

Ethanol

Alcohol

Optimization

Performance

Emission

Gasoline engine
A B S T R A C T

This study, as an observation, put its utmost effort to emphasize on the development of various physicochemical properties using multiple alcohols $\left(C_{2}\right.$ to $\left.C_{6}\right)$ at different ratios compared to that of the conventional ethanol-gasoline blend. To optimize the properties of multiple alcohol-gasoline blends, properties of each fuel were measured first. An optimization tool of Microsoft Excel "Solver" was used for obtaining the optimum blend. Using optimizing tool, three optimum blend ratios were selected which possessed maximum heating value (MaxH), maximum research octane number (MaxR) and maximum petroleum displacement (MaxD). These blends were used for testing in a four cylinder gasoline engine at the wide open throttle condition with varying speeds and compared obtained outcomes with that of E15 (15\% ethanol and $85 \%$ gasoline) as well as gasoline. Optimized blends have shown higher brake torque and brake thermal efficiency (BTE) but lower brake specific fuel consumption (BSFC) than E15. MaxR, MaxD and MaxH blends produced mean $4.4 \%, 1.8 \%$ and $0.4 \%$ increased BTE and mean $4.39 \%, 1.8 \%$ and 2.27\% lower BSFC than that of E15. On the other hand, MaxR, MaxD, MaxH and E15 reduced $4.46 \%, 8.37 \%$, $12.4 \%$ and $17.2 \%$, mean $\mathrm{CO}$ emission and $4.5 \%, 11.81 \%, 8.19 \%$ and $16 \%$ mean $\mathrm{HC}$ emission respectively than that of gasoline. NOx emission of optimized blends was higher than gasoline. However, MaxR, MaxD, MaxH reduced $4 \%, 14.57 \%$ and $20.76 \%$ NOx than that of E15.

2014 Elsevier Ltd. All rights reserved.

\section{Introduction}

For researchers, observers and manufacturers in the field of energy, the replacement of petroleum gasoline with alternative fuels is an important issue resulted increase in petroleum fuel prices, environmental threats from engine exhaust emissions, fossil fuel depletion, the effects of global warming, and energy concerns (Gürü et al., 2009). Apart from this, experts and researchers are also in quest of alternative fuels for diesel engines, another type of internal combustion engines, that have multiple implication with comparison to gasoline engines (Rahman et al., 2014; Rizwanul Fattah et al., 2014a; Sanjid et al., 2013). The implementation of alcohols as alternatives for petrol in spark ignition (SI) engines has been investigated comprehensively. These alcohols improve oxygen content, enhance octane number, and lessen carbon monoxide (CO) emission. As an alternative fuel, ethanol is the most widely

* Corresponding authors. Department of Mechanical Engineering, University of Malaya, 50603 Kuala Lumpur, Malaysia. Tel.: +60 3 79674448; fax: +60 379675317.

E-mail addresses: masum05me@gmail.com, masum079@yahoo.com (B.M. Masum).

http://dx.doi.org/10.1016/j.jclepro.2014.08.032

0959-6526/@ 2014 Elsevier Ltd. All rights reserved. used alcohol (Demirbas, 2009b). It can be pooled combined with gasoline as its simple chemical structure, high octane number and oxygen content, and accelerated flame propagation (Masum et al. 2013b). Many experimental studies have ensured that ethano enhance the engine efficiency, torque, and power. However, its brake specific fuel consumption (BSFC) is higher than that of gasoline (Koç et al., 2009). In many countries, governments have already been mandate the integration of ethanol with gasoline. The Environmental Protection Agency (EPA) issued a waiver that authorizes the incorporation of up to $15 \%$ ethanol into gasoline for cars and light pickup trucks made in 2001 onwards (Wald, 2010). The US Renewable Fuel Standard mandates the production of up to 36 billion gallons of ethanol and advanced bio-fuels by 2022 (Rabobank, 2012). To cope up with increased demand for ethanol, alcohols with increased carbon numbers can be utilized as heightened substitutes because the implement of ethanol as fuel in gasoline engines is mainly limited by its low heating value (LHV). Hence, additional low-LHV fuel must be generated to match a certain power level (Demirbas, 2009a). Alcohols with high carbon numbers, such as propanol and butanol, have a higher LHV than ethanol. On the other side, all of these alcohols can be produced 


\begin{tabular}{|llll|}
\hline Nomenclature & MaxH & Blend of Maximum Research Heating \\
EPA & Environmental protection Agency & BTE & Brake Thermal Efficiency \\
RON & Research Octane Number & EGTs & Exhaust Gas Temperatures \\
RVP & Reid Vapor Pressure & SI & Spark Ignition \\
HoV & Heat of Vaporization & CO & Carbon monoxide \\
LHV & Lower Heating Value & HC & Hydrocarbon \\
$\mathrm{C}_{2}$ & Ethanol & NOx & Nitrogen oxides \\
$\mathrm{C}_{3}$ & Propanol & E15 & 15\%Ethanol $+85 \%$ Gasoline \\
$\mathrm{C}_{4}$ & Butanol & E10 & 10\%Ethanol $+90 \%$ Gasoline \\
$\mathrm{C}_{5}$ & Pentanol & MaxR & Blend of Maximum Research Octane Number \\
$\mathrm{C}_{6}$ & Hexanol & MaxD & Blend of Maximum Research Petroleum displacement \\
\end{tabular}

from coal-derived syngas that is a renewable source (CamposFernandez et al., 2013). Moreover, the concept of biorefinery for higher-alcohol production is to combine ethanol formation via fermentation with the transformation of this simple alcohol intermediate into higher carbon number alcohols (Olson et al., 2004). Higher carbon numbered alcohols, those having lower RON, can also be applied in gasoline engine if ethanol is added as ethanol has higher RON. Thus, multi-alcohol gasoline may provide better outcomes in fuel property as well as engine output. Some authors have emphasized on the potentiality of fuel properties using blends of multiple alcohols with gasoline and got better fuel properties than conventional ethanol gasoline blend (Lawyer et al., 2013a, b).

Some observations and rigorous studies have analyzed the casual relationship of different type of alcohol as a partial alteration of gasoline in SI engine. Gravalos et al. (2013) integrated approximately $1.9 \%$ methanol, $3.5 \%$ propanol, $1.5 \%$ butanol, $1.1 \%$ pentanol, and variable concentrations of ethanol with gasoline in a singlecylinder gasoline engine. A total of 30\% alcohol was incorporated into the gasoline. The alcohol-gasoline blend emitted less $\mathrm{CO}$ and $\mathrm{HC}$ but more NOx and $\mathrm{CO}_{2}$ than pure gasoline. In this paper, multiple alcohol-gasoline blends also emit more acceptable levels of CO and HC than the ethanol-gasoline blend. Yacoub et al. (1998) integrated methanol, ethanol, propanol, butanol, and pentanol with gasoline in an engine and explained and analyzed its performance and emissions. Each alcohol was blended with gasoline containing $2.5 \%$ and $5 \%$ oxygen. The alcohol-gasoline blend displayed better BTE, knock resistance, and emissions than gasoline, but its BSFC was higher. Alcohols with low carbon content (e.g. C1, C2, and C3) contain high levels of oxygen. Hence, relatively less of these alcohols are required to meet the targeted oxygen percentage than alcohols with high carbon content (e.g., C4 and C5). Alcohol percentage and properties differed for the variation in blends. Thus, different alcohol-gasoline blends cannot be compared properly under optimized oxygen concentrations. Gautam et al. (2000) prepared six alcohol-gasoline blends with various proportions of methanol, ethanol, propanol, butanol, and pentanol that total $10 \%$ alcohol. The alcohol-gasoline blends emitted lower brake specific $\mathrm{CO}, \mathrm{CO}_{2}$, and $\mathrm{NOx}$ than pure gasoline. However, these experts and researchers did not blend specific volume percentages of alcohol or consider fuel properties.
However, researchers and observers did not blend different alcohols in any specific percentage to develop and improve blend properties. No research has been conducted considering improvement fuel properties of the multi alcohol gasoline blend. There is a lack of research on optimization of fuel properties of multiple alcohol-gasoline blends and their effect on engine performance and emission. Nonetheless, the derivation of alcohols with high carbon numbers from renewable sources has increasingly been investigated (Ammar, 2013; Grotkjaer et al., 2011; Jain and Yan, 2011; Komonkiat and Cheirsilp, 2013; Lan and Liao, 2013). In particular, the application of such alcohols as gasoline engine fuel must be subject to meticulous and extensive examination and experiments. Thus, this research puts its utmost effort and concentration to obtain optimized blends of ethanol, propanol, butanol, pentanol, hexanol and gasoline blend as alternative of E10/E15 blend and analyze the effect of optimized blends on engine performance and emission with respect to E15 and gasoline.

\section{Materials and method}

\subsection{Fuel selection}

In this study, we choose ethanol, propanol, butanol, pentanol and hexanol (99.8\% purity). We utilized branched isomers of propanol, butanol and pentanol as they have higher octane numbers. However, straight ( $\mathrm{n}-)$ isomer for hexanol was taken for this study due to its low cost compared to iso-hexanol. Gasoline with research octane number (RON) 95 was used as the base gasoline.

\subsection{Measurement of fuel properties and prediction method}

To identify the optimum blend, we must determine the physiochemical properties of alcohol-gasoline blends in relation to engine operation. In the evaluation of fuel, density, LHV, HoV, RON, and RVP are vital to customer satisfaction, engine and legislative requirements, and the maintenance of industry standards. Thus, these fuel properties were compared in fuels containing volumetric amounts of different alcohols, including E15. In this experiment, fuel properties were measured by implementing various

Table 1

Apparatus used for testing fuel properties.

\begin{tabular}{|c|c|c|c|}
\hline Property & Equipment & Manufacturer & Standard method \\
\hline Density at $15^{\circ} \mathrm{C}$ & DM40 LiquiPhysics'M density meter & Metter Toledo, Switzerland & ASTM D 4052 \\
\hline Lower heating value & C2000 basic calorimeter-automatic & IKA, UK & ASTM D240 \\
\hline Reid vapor pressure at $37.8^{\circ} \mathrm{C}$ & Setavap 2 automatic vapor pressure tester & Paragon Scientific Ltd, UK & ASTM D5191 \\
\hline
\end{tabular}


Table 2

Properties of fuels.

\begin{tabular}{|c|c|c|c|c|c|c|c|}
\hline Property & Unit & Gasoline & Ethanol & Iso-propanol & Iso-butanol & Iso-pentanol & n-hexano \\
\hline Oxygen & wt\% & 0 & 34.7 & 26.6 & 21.6 & 18.1 & 15.7 \\
\hline Density & $\mathrm{Kg} / \mathrm{m}^{3}$ & 736.8 & 794.3 & 789.4 & 806 & 812.5 & 822.2 \\
\hline LHV & $\mathrm{MJ} / \mathrm{kg}$ & 43.919 & 28.793 & 32.947 & 35.689 & 37.622 & 38.968 \\
\hline $\operatorname{RVP}\left(\right.$ at $\left.37.8^{\circ} \mathrm{C}\right)$ & $\mathrm{kPa}$ & 63.9 & 19.1 & 13.8 & 6.6 & 2.9 & 2.8 \\
\hline Latent heat of vaporization & $\mathrm{kJ} / \mathrm{kg}$ & 349 & 923 & 761 & 683 & 621 & 484 \\
\hline Specific gravity & & 0.7375 & 0.795 & 0.7899 & 0.8067 & 0.8132 & 0.8229 \\
\hline
\end{tabular}

apparatuses, as detailed in Table 1. Fuel RON was provided by the suppliers, and Table 2 demonstrates the properties of the gasoline and other alcohols.

Under fundamental assumptions regarding the mixture, we directly measured some of these properties, including density, LHV, $\mathrm{HoV}$, and oxygen content. These calculations remain straightforward regardless of the number of components in the blend because the properties of these components are linearly combined. However, other properties are difficult to compute, including distillation profile, RON, and RVP. Thus, we explain the calculation procedure of these non-linear properties in this section.

The properties of the blend components are linearly related to density, LHV, HoV, and oxygen content. Hence, we use Equation (1) to compute these properties.

property $_{\text {blend }}=\sum_{i=1}^{n} v_{i} \times$ property $_{i}$

The volumetric integration of alcohol with gasoline nonlinearly modifies octane number (Szybist et al., 2010). Therefore, Anderso et al. (2010) proposed molar alcohol concentration as a more suitable calculation to explain the dependence of RON and motor octane number on alcohol content. They simplify the calculation of RON by considering the molar fraction of alcohol in a blend. In Equation (2), $x_{\text {alc }}$ is the molar fraction of alcohol in the blend.

$\mathrm{ON}_{\text {blend }}=\left(1-x_{\mathrm{alc}}\right) \mathrm{ON}_{\mathrm{base}}+\left(x_{\mathrm{alc}}\right) \mathrm{ON}_{\mathrm{alc}}$

The vapor pressure of the ethanol-gasoline blend is complicated to calculate as its solution is complex and non-ideal. To

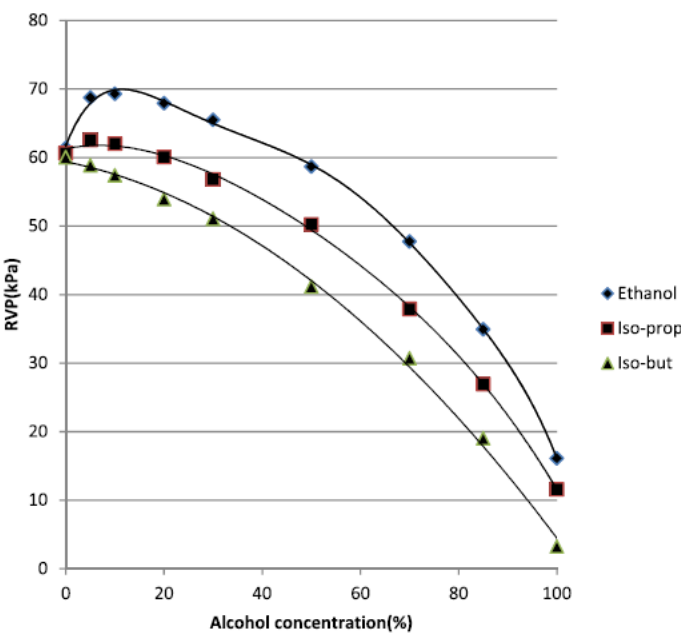

Fig. 1. Estimated gasoline-alcohol blend RVP. profess on this pressure, Reddy (2007) developed a model by implementing the UNIFAC method. We apply this model in the current study. The curves of the alcohols with high carbon number (C3-C6) are drawn based on experimental data and extrapolated in the alcohol-gasoline blend for envisaging the RVP in the blend. Fig. 1 displays the calculated and experimental vapor pressures of different alcohol-gasoline blends.

The blend properties were optimized using Microsoft Excel solver tools. This optimizer solves linear, non-linear, and integer programs within the spreadsheet. In the spreadsheet, the fuel volume concentrations were designated as decision variables, and volume concentration was converted to get the required properties. The equations applied to predict the properties were inputted into Excel solver tools. We explain the target values in the next chapter. The three best combinations from among the optimized combinations were considered for maximum heating value, RON, and petroleum displacement.

\subsection{Target properties for optimum blends}

To make an assessment of this prospect of a substance as a fuel, firstly, it must fulfill the desired properties. Hence, the total alcohol content of a multiple alcohol-gasoline blend must fall within a certain range. In this study, the fuel properties considered are energy content, octane number, oxygen content, petroleum displacement, and vapor pressure. Once these criteria and their target values are implemented, the properties of the multi-component blends are predicted and compared with those targets. We then examine the compositions of blends whose properties meet all of the target criteria. The trends are then noticed and demonstrated in this script.

The E10/E15 alternate scenario aims to identify multicomponent blends that can be implemented in current engines and can enhance petroleum displacement, knock resistance, and/or energy content compared with E10/E15 while adhering to industry standards and consumer expectations. These blends contain adequate oxygen content to meet the EPA E15 waiver, a knock resistance equivalent to that of E10 or higher, vapor pressure that is within the standards of the American Society for Testing and Materials, a minimum energy content equal to that of E15, and petroleum displacement that is at least equal to that of E15. Table 3 summarizes these criteria and their values.

\subsection{Experimental setup}

We experimented on a four-cylinder gasoline engine at the Engine Laboratory of the Mechanical Engineering Department in

Table 3

Target value of optimum blends.

\begin{tabular}{lll}
\hline Properties & Unit & Alternative fuel's target \\
\hline LHV & $\mathrm{MJ} / \mathrm{kg}$ & $\geq 41.65$ \\
RON & - & $\geq 96.24$ \\
RVP & $\mathrm{kPa}$ & 34 to 62 \\
Oxygen content & $\mathrm{wt} \%$ & $\leq 5.205$ \\
Petroleum displacement & $\mathrm{vol. \%}$ & $\geq 15 \%$ \\
\hline
\end{tabular}


Table 4

\begin{tabular}{ll}
\hline Specification of the tested engine. \\
\hline Engine parameter & Value \\
\hline Engine name & Proton Campro \\
Number of cylinder & 4 \\
Displacement volume & $1596 \mathrm{cc}$ \\
Bore & $78 \mathrm{~mm}$ \\
Stroke & $84 \mathrm{~mm}$ \\
Connecting rod length & $131 \mathrm{~mm}$ \\
Compression ratio & $10: 1$ \\
Fuel system & Multi-point electric port fuel system \\
Max output & $78 \mathrm{~kW}$ at $6000 \mathrm{rpm}$ \\
Max torque & $135 \mathrm{~N}$-m at $4000 \mathrm{rpm}$ \\
\hline
\end{tabular}

the University of Malaya. Table 4 lists the details of the engine, and Fig. 2 depicts the schematic of the experimental setup. The test engine was coupled with an eddy current dynamometer (Froude Hofmann model AG150, United Kingdom) with a maximum power of $150 \mathrm{~kW}$. The engine was first operated on gasoline for $15 \mathrm{~min}$ to stabilize the operating condition. The fuel was then changed to the alcohol blend. After sufficient amounts (approximately 1 Litter) of the blend were consumed, data were acquired to ensure the removal of residual gasoline from the fuel line. Each test engine was again operated under gasoline to drain all of the blends in the fuel line.

The engine was operated between $1000 \mathrm{rpm}$ and $6000 \mathrm{rpm}$ with a step of $1000 \mathrm{rpm}$ at $100 \%$ load condition. We measured fuel flow using a KOBOLD ZOD positive-displacement type flow meter (KOBOLD, Germany). The data were automatically collected using the CADET 10 data acquisition system. Exhaust emissions were measured using the AVL DICOM 4000 exhaust gas analyzer (AVL DiTEST, Austria), where $\mathrm{CO}, \mathrm{HC}$ and $\mathrm{CO}_{2}$ are determined by infrared measurement detector and $\mathrm{NOx}$ and $\mathrm{O}_{2}$ determined by electrochemical measurement detector. These measurements were highly repeatable within the test series. In each test, performance and emission were taken measurement for three times.

\section{Calculation methods}

\subsection{Engine performance}

The engine performance is evaluated on torque, BSFC and BTE. The BSFC and BTE were assessed by following equations:

BSFC $=\frac{\text { Fuel consumption }}{\text { Output power }}$
$\mathrm{BTE}=\frac{3600 \times \text { Brake power }}{\text { Fuel consumption } \times \text { LHV }}$

\subsection{Error analysis}

Errors and uncertainties in the experiments can arise from instrument selection, condition, calibration, environment, observation, reading, and test planning. Uncertainty analysis was required to prove the accuracy of the experiments. The calculation arena, accuracy and percentage uncertainties which associated with the instruments implemented in this experiment are enlisted in Table 5. To measure the whole percentage uncertainty due to the integrated impacts of the uncertainties of various variables, the principle of propagation of errors is taken under consideration and can be estimated as $\pm 2.88 \%$. The overall experimental uncertainty was computed as follows (How et al. 2014):

Overall experimental uncertainty $=$ Square root of [(uncertainty of speed $)^{2}+(\text { uncertainty of torque })^{2}+(\text { uncertainty of BSFC })^{2}+$ (uncertainty of BTE $)^{2}+(\text { uncertainty of CO })^{2}+(\text { uncertainty of } \mathrm{HC})^{2}$ $\left.+(\text { uncertainty of NOx })^{2}+(\text { uncertainty of EGT })^{2}\right]=$ Square root of $\left[(0.1)^{2}+(0.25)^{2}+(1.5)^{2}+(1.5)^{2}+(1.0)^{2}+(1.0)^{2}+(1.3)^{2}+(0.15)^{2}\right]$ $=2.88 \%$

\section{Result and discussion}

\subsection{Optimum blend properties}

The three optimum blends with maximum LHV, RON, and petroleum displacement are denoted by MaxH, MaxR, and MaxD, respectively. All three blends reached at the targeted substitute fuel properties which depicted in Table 3. Fig. 3 depicts all of these suitable blends, and Table 6 lists their properties. Compared with the target value, the MaxR blend develops RON by $4.65 \%$, MaxH blend improves LHV by $1.92 \%$, and the MaxD blend improves petroleum displacement by $32.27 \%$.

\subsection{Engine performance}

4.2.1. Torque

Fig. 4 compares the engine torque given the test fuels. On average, alcohol-gasoline blends increase torque than that of gasoline. The maximum brake toque is available in $4000 \mathrm{rpm}$ engine speed and those were $129.3 \mathrm{Nm}, 131.5 \mathrm{Nm}, 129.52 \mathrm{Nm}, 130.9$ $\mathrm{Nm}$ and $131.5 \mathrm{Nm}$ for gasoline, MaxR, MaxD, MaxH and E15 fuel respectively. The enhanced torque may be attributed to the high

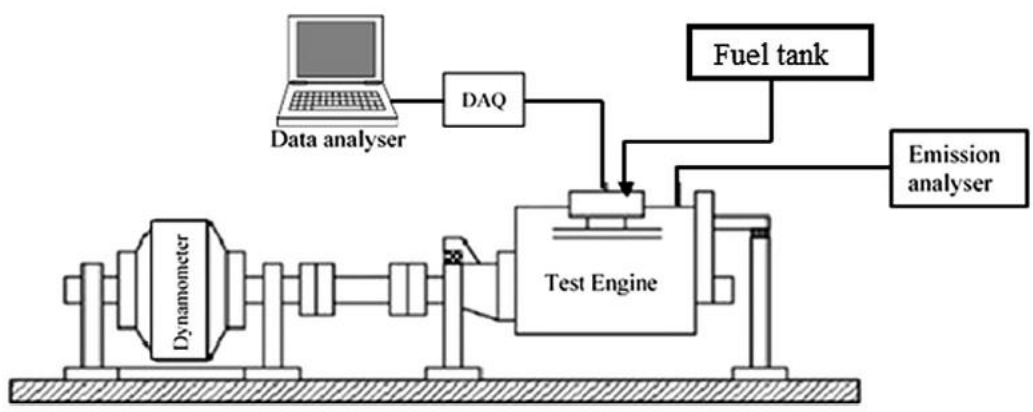

Fig. 2. Schematic diagram of the engine test bed. 
Table 5

List of measurement accuracy and percentage uncertainties.

\begin{tabular}{|c|c|c|c|c|}
\hline Measurement & Measurement range & Accuracy & Measurement techniques & $\%$ Uncertainty \\
\hline Load & $\pm 600 \mathrm{Nm}$ & $\pm 0.1 \mathrm{Nm}$ & Strain gauge type load cell & \pm 0.25 \\
\hline Time & & $\pm 0.1 \mathrm{~s}$ & & \pm 0.2 \\
\hline $\mathrm{CO}$ & $0-10 \%$ vol. & $\pm 0.01 \%$ vol. & Non-dispersive infrared & \pm 1 \\
\hline $\mathrm{HC}$ & $0-2000 \mathrm{ppm}$ & $\pm 1 \mathrm{ppm}$ & Heated flame ionization detector & \pm 1 \\
\hline NOx & $0-5000 \mathrm{ppm}$ & $\pm 1 \mathrm{ppm}$ & Electrochemical & \pm 1.3 \\
\hline Brake power & & $\pm 0.03 \mathrm{~kW}$ & & \pm 0.3 \\
\hline BSFC & & $\pm 5 \mathrm{~g} / \mathrm{kWh}$ & & \pm 1.5 \\
\hline BTE & & $\pm 0.2 \%$ & & \pm 1.5 \\
\hline
\end{tabular}

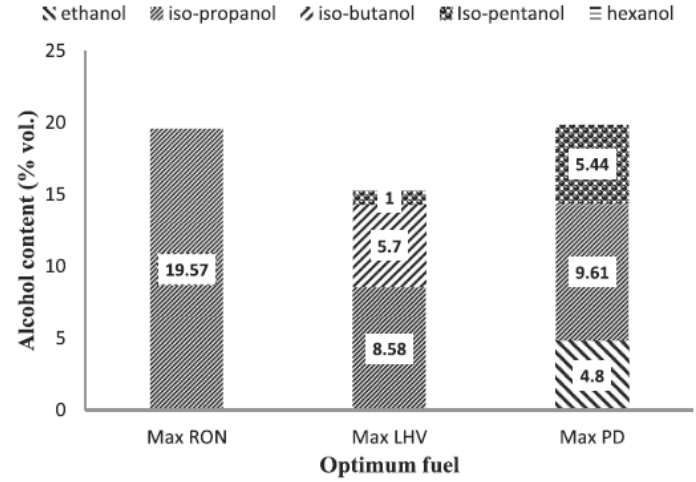

Fig. 3. Composition of the optimum fuels.

latent heat of vaporization ( $\mathrm{HoV})$. Fuel vaporizes in the intake manifold and in the combustion chamber. When the HoV of alcohol increases, charge temperature is lessened because the alcohol evaporates. Furthermore, charge density increases. Engine torque is increased with respected fuel mass at the same air-fuel ratio. This result is same with those found by other researchers (Feng et al., 2013; Schifter et al., 2013). Moreover, the incorporation of oxygenated alcohol produces a lean mixture that burns more efficiently than that the gasoline (Koç et al., 2009). Among all blends, E15 obtained the highest torque, though it has lowest LHV than that of other blends. This improved torque may be attributed to the enhanced RON of ethanol. High RON of ethanol aggravates ignition delay, which decelerates energy release rate and limits heat loss from the engine because the heat from the cylinder is not transferred to the coolant in time (Campos-Fernandez et al.). Hence, engine torque decreases after it is maximized by engine acceleration.

Table 6

Properties of optimum fuels and improvement over target. Bold fonts indicate the main focused properties of corresponding fuel blend that we tried to improve.

\begin{tabular}{|c|c|c|c|c|}
\hline & $\begin{array}{l}\text { Expected } \\
\text { value }\end{array}$ & $\begin{array}{l}\text { Blend\#1 } \\
\text { Max RON }\end{array}$ & $\begin{array}{l}\text { Blend\#2 } \\
\text { Max LHV }\end{array}$ & $\begin{array}{l}\text { Blend\#3 Max } \\
\text { petr. displacement }\end{array}$ \\
\hline RON & $\geq 96.24$ & $100.71(+4.65 \%)$ & $96.24(0 \%)$ & $96.58(+0.35 \%)$ \\
\hline LHV (MJ/kg) & $\geq 41.65$ & $41.77(+0.29 \%)$ & $42.45(+1.92)$ & $41.8(+0.36)$ \\
\hline $\begin{array}{l}\text { Petroleum } \\
\text { displacement } \\
\text { (vol. \%) }\end{array}$ & $\geq 15$ & $19.57(30.47 \%)$ & $15.28(+1.8)$ & $19.85(+32.27)$ \\
\hline
\end{tabular}

42.2. Brake specific fuel consumption

Fig. 5 portrays the difference in the BSFC of the test fuels at diverse engine speeds. It can be observed that gasoline shows the lowest BSFC with comparison to other alcohol gasoline blends with the entire engine speed. Higher LHV of gasoline is potential cause where effect is the lower BSFC of gasoline. It was assessed that the value of minimum BSFC with gasoline is $345.3 \mathrm{~g} / \mathrm{kWh}$. On average, the BSFC values of E15, MaxR, MaxD and MaxH were higher than that of unleaded gasoline by $6.7 \%, 2 \%, 4.76 \%$ and $4.26 \%$, respectively. This obtained outcome is conventionally ascribed to the low energy content of the alcohols, which enhances engine BSFC to obtain same engine power when it is applied without any engine modification (Balki et al., 2014). The high BSFC of alcohol may also be induced by high alcohol density (Koc et al., 2009). Nonetheless, the BSFC of MaxR is closer to that of gasoline than the other alcohols. Furthermore, MaxR, MaxH and MaxD displayed BSFC values that were $5.1 \%, 0.5 \%$ and $1.4 \%$ lower, respectively, than that of E15. With altering more than $15 \%$ gasoline, optimized blends were showed lower BSFC than that of E15. This is because of better fuel properties (e.g. LHV in case of BSFC) of optimized blend. This produced same brake power with lower fuel consumption than that of E15.

\subsubsection{Brake thermal efficiency}

Thermal efficiency indicates the ability of the combustion system to accept the experimental fuel, and provides comparable means of assessing how efficient the energy in the fuel was converted to

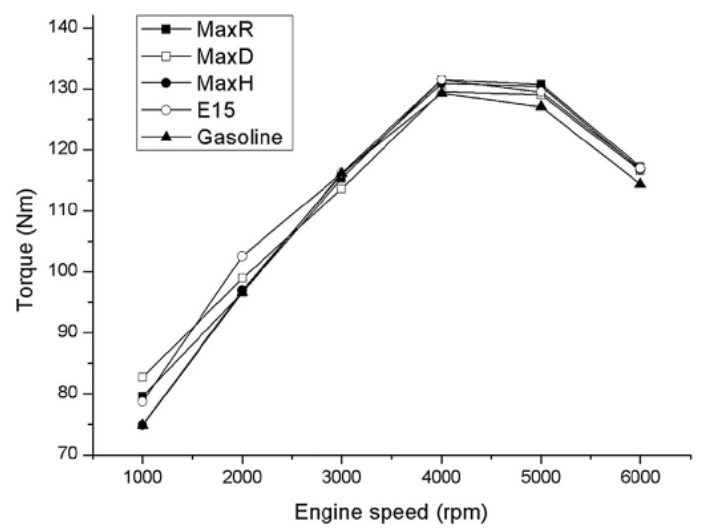

Fig. 4. Variation of torque with engine speed. 
mechanical output (Hulwan and Joshi, 2011). Fig. 6 displays the BTE values of various test fuels. Brake thermal efficiency increased with engine speed until $5000 \mathrm{rpm}$ and maximum thermal efficiency was $24.69 \%, 24.38 \%, 24.42 \%, 24.16 \%$ and $23.74 \%$ when MaxR, MaxD, MaxH, E15 and gasoline were used as fuel respectively. Alcohol-gasoline blends demonstrate higher BTE values than that with gasoline. This condition can be attributed to the findings that alcohols contain oxygen where gasoline has no oxygen. As a result, combustion is improved, thereby enhancing thermal efficiency (Campos-Fernandez et al., 2013). Moreover, fuel is vaporized in the compression stroke when latent $\mathrm{HoV}$ is high. Given that fuel absorbs heat from the cylinder during vaporization, the air-fuel mixture is compressed more easily, thus improving thermal efficiency for alcohol-gasoline blend than that of gasoline. Balki et al. (2014) noted that the HoV and oxygen content of alcohol enhances BTE in alcohol-gasoline blends. In average, MaxR and MaxD blends improve BTE than E15 blend respectively $4.02 \%$ and $1.4 \%$.

\subsubsection{Exhaust gas temperature}

Fig. 7 presents the impact of test fuels on the EGT of the test engine, which is, in fact, a vital pointer of cylinder temperature. EGT can also be applied to assess exhaust emission, particularly of NOx because NOx formation often based on temperature (Rizwanul Fattah et al., 2014b). In this figure, the addition of alcohol to gasoline reduces EGTs. In overall engine condition, EGTs reduced $4.3 \%$, $1.9 \%, 3.6 \%$, and $2.2 \%$ for using MaxR, MaxD, MaxH, E15 respectively than that of using gasoline. The reason of this EGTs reduction is that lower LHV of alcohol. Karabektas and Hosoz (2009) explained, the lower energy content of fuel results in lower EGTs. Few other researches (Topgül et al., 2006; Yücesu et al., 2006) explained, higher RON of alcohol starts in-cylinder combustion earlier that assist utilize more heat of combustion and decreases EGTs than gasoline. In all fuels, EGTs increase with engine speed. Moreover, EGT and combustion temperature enhance because increased amounts of fuel burn at high engine speeds. However, lower EGT is also an advantage of a fuel to use in the engine. Lower EGT indicates the higher utilization of heat in the engine. Lower EGT also reduces exhaust manifold cost.

4.3. Engine emission

4.3.1. $\mathrm{CO}$ emission

Fig. 8 depicts the variation of $\mathrm{CO}$ exhaust emission in relation to the engine speed. At high engine speed, $\mathrm{CO}$ emission is lower in alcohol-gasoline blends than in pure gasoline fuel. The engine has limited time to complete the combustion cycle in high engine speed; thus, higher flame speed of alcohol assist to complete the combustion (Feng et al., 2013: Pechout et al.,2012). As an inevitable outcome of this accelerated flame speed in alcohol, alcohol- gasoline blends emit less $\mathrm{CO}$ at high engine speeds. At low engine speed, gasoline emits lower $\mathrm{CO}$ emission than that of alcohol- gasoline blends as higher LHV of gasoline assists in complete the combustion, as well as low CO emission. This obtained fact is consistent with the findings of previous studies, which utilized ethanol-gasoline blends (Costa and Sodré, 2010). In overall speed range, for using E15, MaxR, MaxH and MaxD, CO emissions are significantly lower than those of gasoline by averages of $4.46 \%$, $8.37 \%, 12.4 \%$ and $17.2 \%$, respectively. Alcohols are oxygenated fuels; therefore, they enhance oxygen content in fuel for combustion. This process generates the "leaning effect", which sharply reduces CO emission (Canakci et al., 2013). Thus, alcohol-gasoline blended fuel emits less $\mathrm{CO}$ than gasoline fuel. Optimized blends also depict better CO emission than E15 specially MaxH blend. Higher LHV of MaxH blend accelerates the combustion procedure which results in low CO emission.
4.3.2. HC emission

Fig. 9 exhibits the emissions of unburned $\mathrm{HC}$ by all test fuels at speeds ranging from $1000 \mathrm{rpm}$ to $6000 \mathrm{rpm}$. These emissions were slightly lower in all alcohol-gasoline blends than in pure gasoline. On average, emissions of unburned HC by E15, MaxR, MaxD and MaxH significantly decreased by $4.5 \%, 11.81 \%, 8.19 \%$ and $16 \%$, respectively. The oxygen content in alcohols enhances the combustion efficiency of alcohol-gasoline blends, which reduces HC emission for using alcohol-gasoline blends (Koç et al., 2009). At the same time, laminar flame speed of alcohol is higher than gasoline (Sayin, 2010). That may assist complete combustion of alcohol-gasoline blend as well as lower HC emission. Moreover, these emissions decrease as engine speed increases in all blends. At high speeds, the air-fuel mixture homogenizes to increase in-cylinder temperature. This condition in turn enhances combustion efficiency (Masum et al., 2014). Thus, HC emission decreases more at high engine speeds than at low speeds. This conclusion is consistent with that of Koç et al. (2009).

\subsubsection{NOx emission}

In the time of combustion process at high temperature, nitrogen in the air oxidizes to form NOx. Thus, the generation of NOx in an engine is closely related to combustion temperature, oxygen concentration, and residence time inside the combustion chamber (Masum et al., 2013a). Fig. 10 exhibits the variation in NOx emission at WOT and at different engine speeds. On average, the increase in NOx emissions is $36.9 \%, 31.4 \%, 16.9 \%$ and $8.47 \%$ for E15, MaxR, MaxD and $\mathrm{MaxH}$ compared to pure gasoline. Higher oxygen concentration might be the reason for higher NOx emission for using alcohol- gasoline blends. In previous sections, it was noticed that, BSFC and BTE was seen higher for alcohol-gasoline blends which indicates higher cylinder temperature for alcohol-gasoline blends than that of gasoline. Higher in-cylinder temperature is the core cause of thermal NOx formation of gasoline engine (Masum et al. 2013b). Yacoub et al. (1998) also discussed, oxygen content of ethanol increase peak in-cylinder pressure as well as NOx emission. It is also observed that optimized blends generate lower NOx than E15 blend.

\section{Conclusion}

The core objective of this study was to develop the energy content, knock resistance, and/or petroleum displacement using multi alcohol-gasoline blend compared to traditional ethanol blends such as E10/E15 while maintaining specified fuel properties. The performance and emission characteristics were measured for those multi-alcohol gasoline blends and compared with gasoline and E15 blend. Based on experimental observation the following conclusion can be made:

- From all multi alcohol-gasoline fuel combination three optimum blends were selected on the basis of maximum LHV, maximum RON and maximum petroleum displacement and these optimized fuels improved LHV, RON and displacement by $1.92 \%, 4.65 \%$ and $32.27 \%$ respectively.

- Optimized blends improved engine torque and BTE than gasoline and E15 because of improved fuel properties such as RON, LHC etc. of optimized blends. MaxR blend showed highest BTE than other blends and the improvement of BTE was 3.36\% than that of gasoline.

- BSFC results of optimized blends are more acceptable than E15. However, MaxR, MaxD and MaxH blends reduced BSFC 4.39\%, $1.8 \%$ and $2.27 \%$ respectively than that of E15 fuel.

- All alcohol gasoline blends emitted lower CO and HC emission than that of gasoline. MaxR, MaxD, MaxH, E15 blend lessened

\section{Link to Full-Text Articles :}

\section{http://www.sciencedirect.com/science/article/pii/S0959652614008543}

